\title{
Stability, Strategy-Proofness, and Cumulative Offer Mechanisms
}

\author{
JOHN WILLIAM HATFIELD, University of Texas at Austin \\ SCOTT DUKE KOMINERS, Harvard University \\ ALEXANDER WESTKAMP, University of Cologne
}

In many-to-one matching with contracts, agents on one side of the market, e.g., workers, can fulfill at most one contract, while agents on the other side of the market, e.g., firms, may desire multiple contracts. Hatfield and Milgrom [6] showed that when firms' preferences are substitutable and size monotonic, the worker-proposing cumulative offer mechanism is stable and strategy-proof (for workers). ${ }^{1}$

Recently, stable and strategy-proof matching has been shown to be possible in a number of real-world settings in which preferences are not necessarily substitutable (see, e.g., Sönmez and Switzer [13], Sönmez [12], Kamada and Kojima [7], and Aygün and Turhan [1]); this has motivated a search for weakened substitutability conditions that guarantee the existence of stable and strategy-proof mechanisms. Hatfield and Kojima [3] introduced unilateral substitutability and showed that when all firms' preferences are unilaterally substitutable (and size monotonic), the cumulative offer mechanism is stable and strategy-proof. Kominers and Sönmez [9] identified a novel class of preferences, called slot-specific priorities, and showed that if each firm's preferences are in this class, then the cumulative offer mechanism is again stable and strategy-proof. Subsequently, Hatfield and Kominers [4] developed a concept of substitutable completion and showed that when each firm's preferences admit a size monotonic substitutable completion, the cumulative offer mechanism is once more stable and strategy-proof.

In this paper, we introduce three novel conditions-observable substitutability, observable size monotonicity, and non-manipulability via contractual terms-and show that when these conditions are satisfied, the cumulative offer mechanism is the unique mechanism that is stable and strategy-proof. Moreover, when the choice function of any firm fails one of our three conditions, we can construct unit-demand choice functions for the other firms such that no stable and strategy-proof mechanism exists.

\footnotetext{
${ }^{1}$ Stable and strategy-proof matching has proven essential for many real-world matching applications (see, e.g., the work of Roth [11], Pathak and Sönmez [10], and Hassidim et al. [2]).
}

The authors appreciate the helpful comments of Ran Eilat, Ravi Jagadeesan, Fuhito Kojima, Shengwu Li, Paul Milgrom, Alvin E. Roth, Larry Samuelson, Jan Christoph Schlegel, Bertan Turhan, and seminar audiences at the American Economic Association Meetings, MATCH-UP, the Society for Economic Design, Caltech, Innsbruck, North Carolina State, Paris Dauphine, Sabanc1, Stanford, and Texas A\&M. Kominers gratefully acknowledges the support of National Science Foundation grants CCF-1216095 and SES-1459912, the Harvard Milton Fund, and the Ng Fund of the Harvard Center of Mathematical Sciences and Applications. Westkamp gratefully acknowledges funding from the People Programme (Marie Curie IntraEuropean Fellowship) of the European Union's Seventh Framework Programme (FP7/2007-2013) under REA grant agreement 628276.

Authors' addresses: J. W. Hatfield, McCombs School of Business, University of Texas at Austin, 2110 Speedway, Austin, TX 78172, john.hatfield@utexas.edu; S. D. Kominers, Society of Fellows, Department of Economics, Center of Mathematical Sciences and Applications, and Center for Research on Computation and Society, Harvard University, and Harvard Business School, Arthur Rock Center for Entrepreneurship, Soldiers Field, Boston, MA 02163, kominers@fas.harvard.edu; A. Westkamp, Department of Management, Economics, and Social Sciences, University of Cologne, Albertus-Magnus-Platz, 50923 Cologne, Germany, acwestk@gmail.com.

Permission to make digital or hard copies of part or all of this work for personal or classroom use is granted without fee provided that copies are not made or distributed for profit or commercial advantage and that copies bear this notice and the full citation on the first page. Copyrights for third-party components of this work must be honored. For all other uses, contact the owner/author(s).

EC'17, fune 26-30, 2017, Cambridge, MA, USA. (C) 2017 Copyright is held by the owner/author(s).

ACM ISBN 978-1-4503-4527-9/17/06. DOI: http://dx.doi.org/10.1145/3033274.3084085 
Our results give the first characterization of sufficient and necessary conditions for the guaranteed existence of stable and strategy-proof mechanisms for many-to-one matching with contracts. Our conditions are strictly weaker than the previously known sufficient conditions for the existence of stable and strategy-proof mechanisms; this enables new applications, as well as a new interpretation of prior models of matching with distributional constraints (Hatfield et al. [5]; see also Kamada and Kojima [7, 8]). Additionally, our work gives a foundation for the use of cumulative offer mechanisms in many-to-one matching markets with contracts: Whenever a stable and strategy-proof matching mechanism exists, either it must coincide with a cumulative offer mechanism, or its stability and/or strategy-proofness depends crucially on some specific interdependence of preferences across hospitals that rules out certain unit-demand choice functions.

Full Paper: http://www.scottkom.com/articles/Hatfield_Kominers_Westkamp_Stability_Strategy-Proofness.pdf

\section{CCS Concepts: •Applied computing $\rightarrow$ Electronic commerce; Economics;}

Additional Key Words and Phrases: Matching with contracts; Stability; Strategy-proofness; Substitutability; Size monotonicity; Cumulative offer mechanisms

\section{REFERENCES}

[1] Orhan Aygün and Bertan Turhan. Forthcoming, 2017. Large Scale Affirmative Action in School Choice: Admissions to IITs and its Matching-Theoretical Problems. American Economic Review Papers \& Proceedings (Forthcoming, 2017)

[2] Avinatan Hassidim, Assaf Romm, and Ran I. Shorrer. Forthcoming, 2017. Redesigning the Israeli Psychology Master's Match. American Economic Review Papers \& Proceedings (Forthcoming, 2017).

[3] John William Hatfield and Fuhito Kojima. 2010. Substitutes and Stability for Matching with Contracts. Journal of Economic Theory 145, 5 (2010), 1704-1723.

[4] John William Hatfield and Scott Duke Kominers. 2016. Hidden Substitutes. (2016). Working paper.

[5] John William Hatfield, Scott Duke Kominers, and Alexander Westkamp. Forthcoming, 2017. Stable and Strategy-Proof Matching with Flexible Allotments. American Economic Review Papers \& Proceedings (Forthcoming, 2017).

[6] John William Hatfield and Paul Milgrom. 2005. Matching with Contracts. American Economic Review 95, 4 (2005), 913-935.

[7] Yuichiro Kamada and Fuhito Kojima. 2015. Efficient Matching under Distributional Constraints: Theory and Applications. American Economic Review 105, 1 (2015), 67-99.

[8] Yuichiro Kamada and Fuhito Kojima. Forthcoming, 2017. Recent Developments in Matching with Constraints. American Economic Review Papers \& Proceedings (Forthcoming, 2017).

[9] Scott Duke Kominers and Tayfun Sönmez. 2016. Matching with Slot-Specific Priorities: Theory. Theoretical Economics 11, 2 (2016), 683-710.

[10] Parag A. Pathak and Tayfun Sönmez. 2008. Leveling the Playing Field: Sincere and Sophisticated Players in the Boston Mechanism. American Economic Review 98, 4 (2008), 1636-1652.

[11] Alvin E. Roth. 2008. Deferred Acceptance Algorithms: History, Theory, Practice, and Open Questions. International Journal of Game Theory 36, 3-4 (2008), 537-569.

[12] Tayfun Sönmez. 2013. Bidding for Army Career Specialties: Improving the ROTC Branching Mechanism. Fournal of Political Economy 121, 1 (2013), 186-219.

[13] Tayfun Sönmez and Tobias B. Switzer. 2013. Matching with (Branch-of-Choice) Contracts at United States Military Academy. Econometrica 81, 2 (2013), 451-488. 